\title{
Equitable bikeway expansion: Investigating potential links to gentrification and displacement
}

\author{
Lizzette Soria, ${ }^{1, *}$ Jesse Cohen, ${ }^{2}$ Maria Fernanda Molas y Molas, ${ }^{3}$ Mena Rizk, ${ }^{4}$ and Prathito Wisambodhi ${ }^{5}$ \\ Edited by Emmett McKinney and Yana Petri
}

\section{HIGHLIGHTS}

- Bicycle infrastructure development has expanded in recent years as a key strategy to foster sustainable urban transportation. However, activists have raised concerns about the risk of gentrification and displacement for low-income communities and communities of color.

- The relationship between bikeway expansion and gentrification is critical for assessing public investment in sustainable transport. However, cities struggle to capture this relationship due to limitations of quantitative data and disagreement on the definition of gentrification.

- Using data on bikeway development from 2010-2015 in Los Angeles, we find a negligible correlation between bikeway development and gentrification or displacement. In light of this finding, we expand on previous scholarship by highlighting the inherent limitations of quantitative metrics for capturing a complex socioeconomic phenomenon such as gentrification.

- Finally, we enumerate how disaggregated data and qualitative methods can help transportation planners and local governments better understand the relation between bikeway expansion and gentrification-and reduce potential differentiated negative impacts.

Many cities across the globe are developing bikeways as a key strategy to reduce greenhouse gas emissions and foster sustainable transportation. However, planners and community activists have raised concerns that bikeway expansion may induce gentrification and displacement,

\footnotetext{
1 United Nations

2 School of the Environment, Yale University, New Haven, CT, US

3 Department of Architecture, Catholic University of Córdoba, Argentina

${ }^{4}$ Department of Mechanical and Industrial Engineering, University of Toronto, Canada

5 Department of Urban Studies and Planning, Massachusetts Institute of Technology, Cambridge, MA, US

*Email: lizzette.soria@gmail.com
}

The authors declare no conflict of interest.

(C) 2021 The Author(s) disproportionately affecting low-income communities and communities of color. While scholars have explored quantitative measurements of this relationship, the metrics fail to capture the nuances and complexity of gentrification as a socioeconomic phenomenon. Our analysis in Los Angeles (LA) examines the correlation between bikeway expansion and gentrification between 2010 and 2015. The findings suggest a minimal correlation between bikeway expansion and gentrification in the surrounding area. This brief provides policy considerations and future research recommendations. These include i) collecting and maintaining detailed bicycle infrastructure data, ii) assessing the relationship between bikeways and other key variables of wellbeing (e.g., housing, accessibility to services, health, and safety) through qualitative data, and iii) implementing meaningful participatory processes with diverse communities.

A round the world, cycling has become popular as an environmentally sustainable, affordable, and healthy mobility option. At a global level, the United Nations calls for low-carbon mobility, including walking and cycling, as a key strategy to achieve the sustainable development goals outlined in its 2030 Sustainable Agenda [1].

At the national and local levels, many government authorities have prioritized expanding bicycle infrastructure to meet greenhouse gas (GHG) emissions targets and to foster road safety as well as health and economic benefits [2]. A recent study conducted by the Institute for Transportation and Development (ITDP) suggests that cycling alone could help cut carbon emissions from urban transportation by $11 \%$ by 2030. The study calls for a global expansion of urban bicycle infrastructure [3], including bikeways, which are the focus of our analysis.

However, during the last decade, transport justice advocates have highlighted the need to understand how bikeway development (along with all other mobility options) fits into a long history of mobility discrimination, injustice, and inequality [4,5]. The complex links between transportation access, housing, race, safety, and economic justice call for an assessment of the relationship between gentrification and cycling infrastructure as an urban development strategy [6].

To better inform inclusive transport investments in Southern California, we explore whether the expansion of bikeways between 2010 and 2015 in LA is associated 
with the displacement of low-income residents in nearby neighborhoods.

\section{Bikeways, Gentrification, and Displacement}

Research suggests that there is a connection between transportation development (particularly public transit) and gentrification. One hypothesis is that improvements in transportation accessibility are desirable to prospective residents, leading to increased accessibility, housing competition, and growing property values [7]. Following this hypothesis, many transport justice advocates and community activists have called attention to the fact that public transportation upgrades often prioritize the needs of prospective middle- to upper-class residents and therefore increase gentrification and displacement of long-term, lower-income residents $[4,5,8]$.

However, researchers and advocates disagree on a common definition of gentrification and how it should be measured. A body of scholars agrees on the broad definition of gentrification as "migration to or from dwellings within given neighborhoods across a fixed period" [9]. Displacement, which can often follow gentrification, is further defined when "any household is forced to move from its long-term residence by conditions beyond its control" (e.g., hazardous conditions or unaffordability) [10].

Furthermore, quantitative scholars have struggled to quantify gentrification empirically [10]. There are important limitations to the measurement of gentrification and displacement using only quantitative methods. A major limitation to most quantitative measurements of gentrification and displacement is their inability to capture the intangible social isolation and disenfranchisement that may coerce residents to leave a gentrifying community [7]. For example, most quantitative measurements fail to capture the "psycho-social ties which bind people to places" [11] and to distinguish the difference between "voluntary" and "involuntary" migration [9].

Urban sociologists and anthropologists further highlight the historical, cultural, and social dimensions behind displacement and gentrification, and stress the political implications behind the term $[4,5,8]$. For example, Schlichtman et al. further explain gentrification as a "complex mixture of migration, transformation, and investment; forced migration and displacement; class, racial, and ethnic transformation; and investment of new residents to the exclusion of older residents" [8]. Advocates and community organizers have relied on qualitative data to build a comprehensive understanding of the issue and to identify potential negative impacts of bicycle infrastructure in diverse communities [6].

\section{Geospatial Analysis in Los Angeles}

Over the past few years, Los Angeles has experienced a dramatic increase in biking and public transportation investment. Between 2005 and 2015, bikeway mileage more than doubled from 245 to 562 miles [12]. Moreover, programs like Livable Streets, as well as plans such as the Mobility Plan 2035 and the Vision Zero Action Plan reflect LA's mission to provide safe streets for a better cycling experience. While studies exist on the relationship between rail transit expansion and neighborhood change in Greater LA, similar studies on the expansion of bikeways remain limited $[13,14]$.

\section{Methodology}

We focus on analyzing the correlation between bikeway expansion and gentrification as opposed to determining whether bikeways cause gentrification [9], given the complexity in determining causality noted earlier. In addition, we examine the correlation between bikeway development and eviction to better capture the complex relationship between gentrification and displacement.

These relationships are analyzed at the census tract level by determining the correlation coefficient between changes in gentrification, displacement, and bicycle infrastructure over the period of 2010 to 2015 . We chose these five years based on bikeway data availability from the Southern California Association of Governments (SCAG) [15] and the City of Los Angeles Geohub [16].

To measure gentrification, we apply the methodology introduced by Chapple et al. [17], using census data for 2010 and 2015 from the American Community Survey [18]. We favored this approach for the analysis given that it was specifically devised for quantifying gentrification in the LA region and it was reproducible with the data accessible to us.

A census tract is defined as gentrified if the magnitude of the change between 2010 and 2015 for all four of the following criteria within the census tract exceeds the county average:

1) Population with a college education (as a percentage),

2) The non-Hispanic white population (as a percentage),

3) Median household income, and,

4) Median gross rent.

Displacement in LA was approximated by quantifying changes in eviction rates over time at the census tract level. Using data from the Eviction Lab at Princeton University [19], we modeled the census tract-level change in displacement as the change in the past 3-year average eviction rate between 2010 and 2015. However, eviction rate is an imperfect measure of displacement for two main reasons.

First, eviction only applies to renters, not homeowners. Proposition 13 (1), [20] in the California State Constitution substantially shields homeowners from increases in property taxes that may result from gentrification and higher property values. However, an increase in the local cost of living as well as the social isolation from socioeconomic shifts in a neighborhood may be strong drivers of displacement of homeowners.

Second, displacement can still be involuntary without necessarily being due to eviction. For instance, residents moving in advance of a proposed redevelopment or in response to a higher cost of living may not be captured in the eviction data. Nevertheless, obtaining more nuanced data on displacement at a local scale is notoriously difficult, making eviction rates a justifiable proxy for displacement [7]. 
We aggregate the change in bikeway development to the census tract level excluding census tracts within an 800-meter circular radius from a Los Angeles metro station, as they may have experienced major infrastructure upgrades that could have also induced gentrification, thus confounding our analysis. This filter removed 375 census tracts in LA. We removed an additional 13 tracts due to incomplete data on the 4 gentrification measures in the American Community Survey dataset. The resulting sample included 833 census tracts.

The bikeway data, sourced from the Los Angeles City Geohub [16] classifies bikeways into 4 categories: Class I are off-road bikeways exclusive to biking and other recreational activities; Class II are designated bicycle lanes on roads shared with vehicles; Class III are bikeways that are shared with vehicles and other road users; and, Class IV are on-road protected bikeways that are physically separated from vehicle travel lanes by more than the white stripe. Given that Class III bikeways provide minimal protection to cyclists, and are barely an improvement to normal vehicle roads, all Class III bikeways were removed from the dataset.

Each census tract has a value indicating the change in bikeway development between 2010 and 2015, normalized by the census tract's area. We measure the change in each census tract by computing the length of the remaining bikeways that are covered within the tract, including an 800 -meter radius beyond the census tract's boundary. This removes edge effects which discount bikeways that are located along the edge of a census tract.

Bikeway aggregation is prone to edge effects as most bikeways run along major streets that are coterminous with census tract boundaries [21]. Moreover, including bikeways beyond a census tract boundary approximates cycling accessibility for each census tract to surrounding tracts within a 5-minute biking distance. We would thus expect any gentrification effects from bicycle infrastructure to spill over as well.

We recognize several limitations to our method. First, some census tracts have a large mileage of bicycle infrastructure and sparse housing. Since such tracts would not be expected to gentrify even with high bikeway mileage, normalizing by area may obscure the hypothesized correlation.

Second, measuring bikeways' connectivity benefit by length does not capture accessibility to points of interest for cyclists. Commonly used accessibility metrics, such as gravity models, are useful at a neighborhood scale but too computationally costly for a city-wide study [22].

A third limitation concerns timing. To the extent that gentrification lags infrastructure development, that relationship could be underrepresented in our data.

The relationship between gentrification and bikeways is measured by determining the point biserial correlation coefficient between the two variables on the census tracts in LA. The point biserial correlation coefficient is a statistical measure of a correlation that is used when one variable is dichotomous and the other is continuous. In our case, the dichotomous variable is the binary gentrification classification and the continuous variable is the change in normalized bikeway mileage from 2010-2015.

\section{Key Findings}

Our study found effectively no correlation between bikeway development and gentrification (0.005 points biserial correlation coefficient) or between bikeway development and the displacement proxy of change in eviction rate $(0.109$ correlation coefficient).

In part, this finding reflects the fact that the census tracts in our sample experienced relatively little change across metrics of gentrification and displacement during this period. As shown in Figure 1. and Table I. below, while normalized bikeway length grew by $187 \%$ between 2010 and 2015 across the census tracts included in the analysis, the only gentrification-related metric to grow significantly during this period was median rent, which was largely driven by increases in a small number of census tracts. Furthermore, only $15 \%$ of the 833 census tracts were considered to have gentrified between 2010 and 2015. Eviction rates dropped by half on average, and almost $75 \%$ of census tracts experienced a drop in eviction rates.

While our study suggests a negligible correlation between bikeway development and either gentrification or displacement, it is by no means conclusive. As previously discussed, there is no strong consensus to define and measure gentrification and displacement. And while these gentrification metrics offer some insight into neighborhood characteristics, they are not exhaustive. While eviction serves as one proxy for physical displacement, it is imperfect for the reasons explained earlier [7].

\section{Moving Forward}

This study demonstrates key limitations of using purely quantitative metrics to measure a complex socioeconomic phenomenon such as gentrification.

In the future, cities can maximize the success of sustainable transport by adopting a comprehensive understanding and approach to anti-displacement. Doing so requires collecting better quantitative and qualitative data for bicycle planning and policy design.

For example, in our quantitative analysis, we identified the need to improve the availability of longitudinal data to measure housing turnover and higher quality tracking of bicycle infrastructure data

A more representative demographic dataset could also reduce the margin of error within the American Community Survey dataset [24], which will increase the analysis' precision. Beyond data quality, quantitative researchers can continue to develop and enhance approaches to quantitatively measure gentrification [25,26], displacement [9], and bikeways' utility [27] (including survey-based methodologies). For example, considering the density of the bike network or cycling accessibility metrics can capture the 


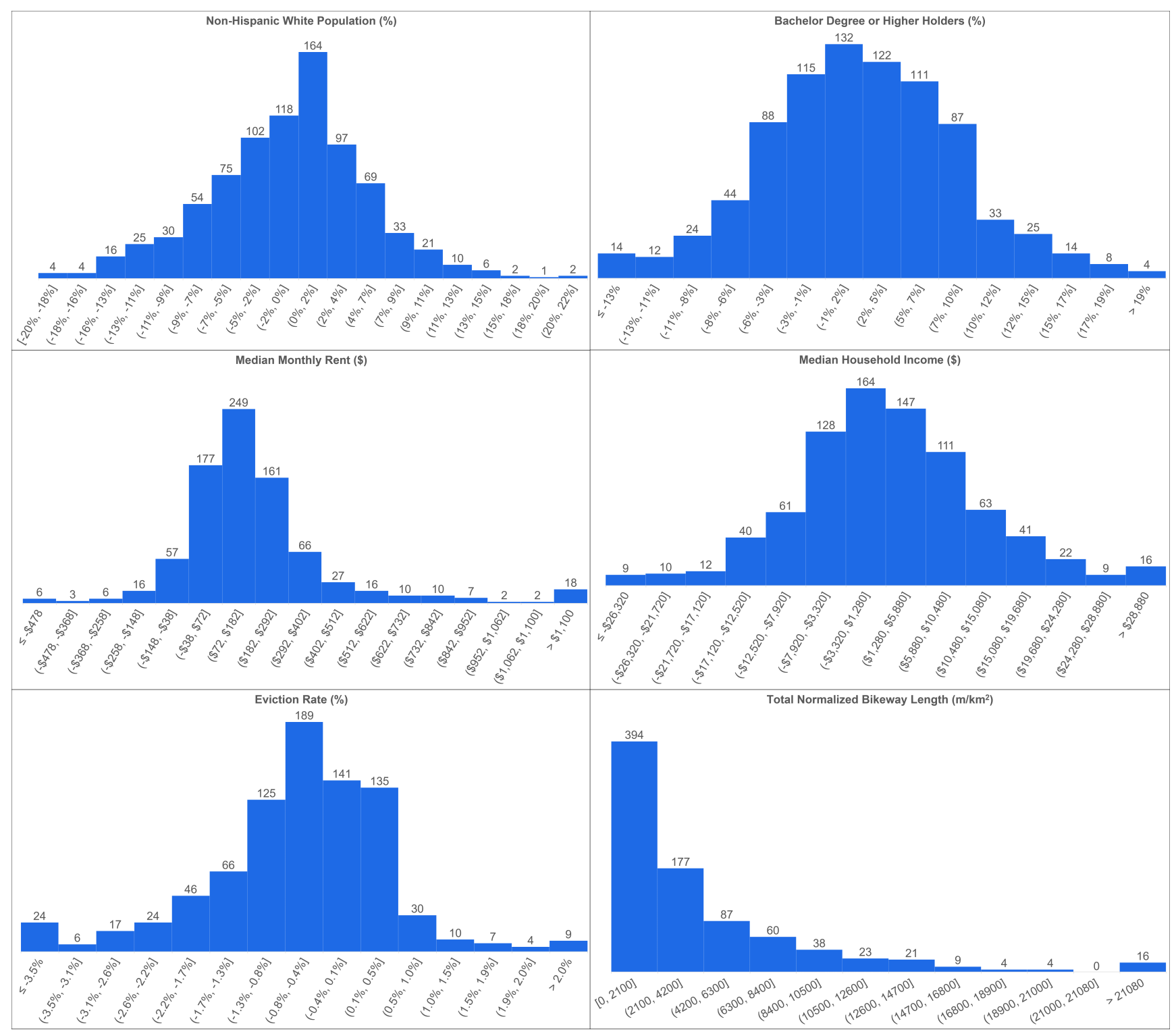

Figure 1: Histogram of absolute change values of gentrification indicators, eviction rate, and normalized bikeways length of census tracts in sample $(n=833)$. The lower and upper bounds of each bin are shown in the horizontal axis under the bars. The number at the top of each bar represents the count of census tracts with an absolute change value that is larger than the lower bound and less than or equal to the upper bound of the bar's respective bin. [16, 18, 19,23]

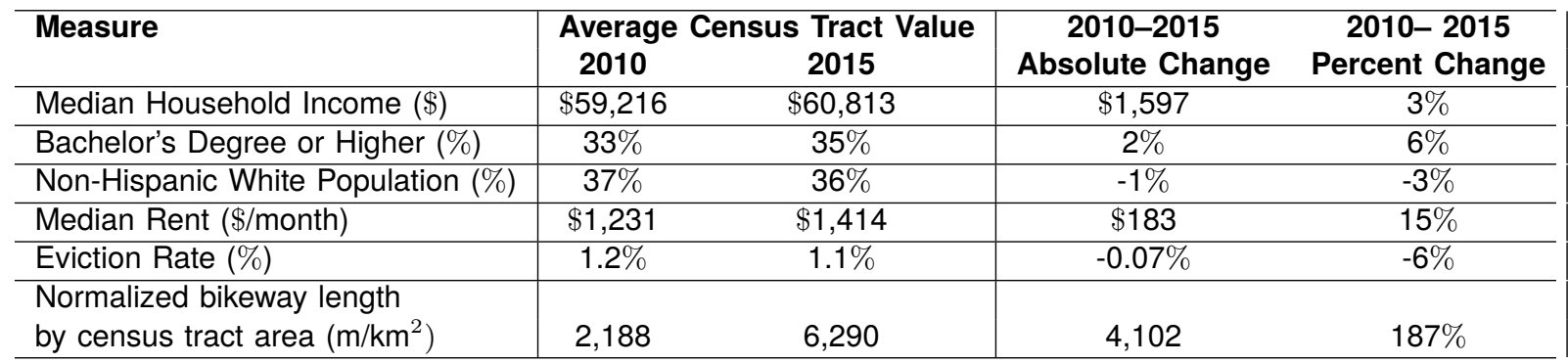

TABLE I: Average values of gentrification indicators, eviction rate, and normalized bikeway length in dataset $(n=833)$. [16, 18, 19, 23] 


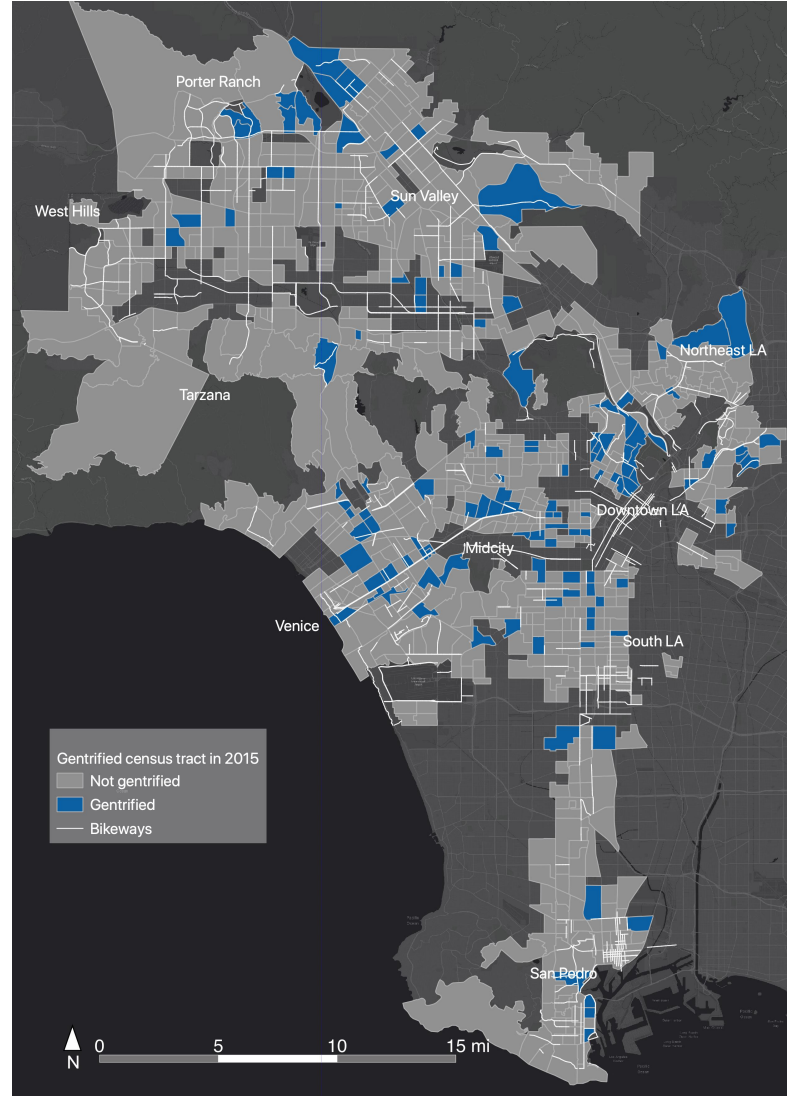

Figure 2: Gentrified census tracts in Los Angeles between 2010-2015 [18,23].

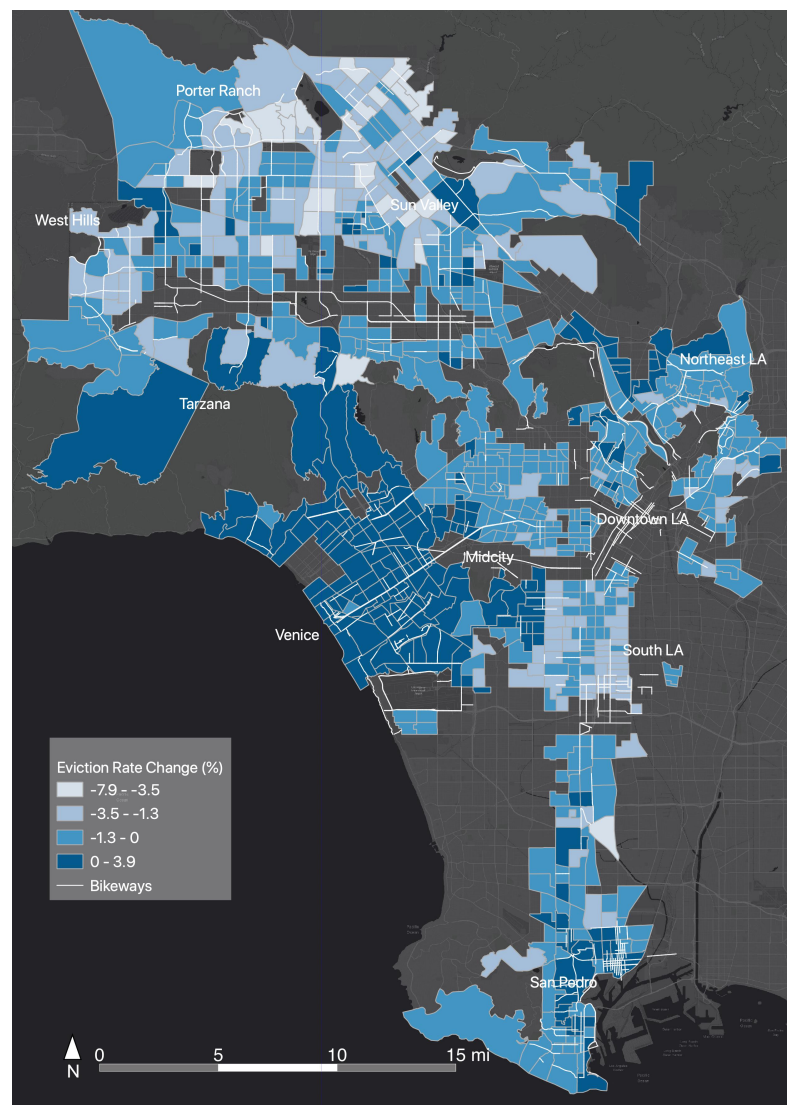

Figure 3: Change of eviction rate in Los Angeles between 2010-2015 [19,23].

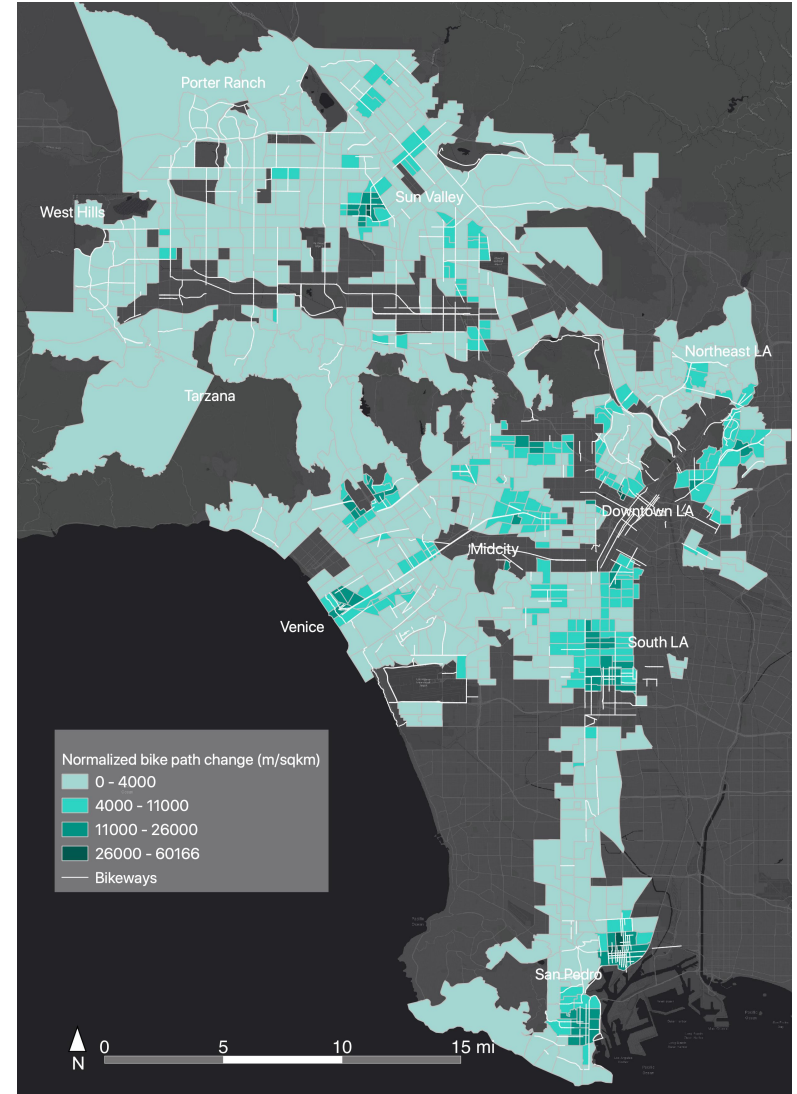

Figure 4: Change of bike path normalized by census tract area in Los Angeles between 2010-2015 [16, 23].

utility of bikeways as a network instead of a single segment of infrastructure.

Qualitative data has the potential to address some of the limitations of purely quantitative approaches to measuring the relationship between bikeway expansion and gentrification. Throughout the last decade advocates and planners have relied on qualitative research-including ethnographic exploration, case studies, and journalism-to deepen the understanding of social isolation, disenfranchisement, and discrimination inherent in gentrification processes.

Inferring bikeway expansion's benefit from aggregated data alone can provide a misleading picture. A 2019 study identified that American cities that had added protected bikeways from 2000 to 2012 saw dramatic reductions in traffic fatalities, but a large proportion of the safety improvements could be explained by changing demographics [28]. The cities that were adding a huge amount of bikeways were getting whiter, and white people are less likely to be killed in traffic than people of color. While attributing this disparity to differences in infrastructure quality [29], researchers question whether the effect was white people outbidding people of color for homes near existing bikeways, or if newly white neighborhoods were better able to secure that infrastructure after moving in. Disaggregated data and qualitative research can further shed light on this important connection between bikeway expansion, its perceived benefits, and potential neighborhood change. 
Qualitative data also highlight important indicators of bikeway expansion's risks and benefits that are harder to quantify. These includes subjective variables like the perception of safety. An anthropologist describes how Latino bicyclists in LA feel unsafe in the streets and choose to ride their bikes on the sidewalks, calling attention to the fact that pursuing "better streets" through law enforcement and safety infrastructure may not necessarily increase safety for all [4].

In the absence of data disaggregated by demographic groups, qualitative data offers a more nuanced analysis on how investments in bikeways may uproot marginalized communities, or deter them from moving to a particular neighborhood. Analysts can use qualitative data to understand interrelated socioeconomic factors of gentrification beyond the fields of housing, wealth, and education.

A study across US metropolitan areas suggests that the benefits of more "active" transportation methods (biking or walking) can depend largely on traffic and road conditions (road safety and motor vehicle exhaust). White populations self-reported greater health outcomes from active transportation relative to Black respondents. This differentiated impact was associated with worse transport infrastructure and pollution levels in Black neighborhoods [30].

Ethnographic studies may also help to understand experiences of minoritized communities who are at the intersection of simultaneous oppressions including (but not limited to) race, class, caste, gender, ethnicity, sexuality, disability, nationality, immigration status, geographical location, and/or religion. For example, bicycle advocates such as Tamika Butler and Melody L. Hoffman have raised concerns around the higher risks that LGBTQI cyclists face in being targeted by police profiling through traffic stops [5, 31].

Furthermore, advocates and community members have used qualitative analyses to understand why investments in bikeways have failed to bring benefits to communities of color. One example comes from a journalist writing about LA's Wilmington neighborhood [32].

Wilmington, situated west of Long Beach, is a largely non-white area with low educational attainment and low median household income. Our study showed that some of the largest bikeway developments in the early 2010 s occurred in Wilmington, with no evidence of accompanying gentrification. While this seems like a positive outcome, the journalist writing about these developments notes that the neighborhood's proximity to trucking and other port-related industries causes air pollution and safety concerns for cyclists, limiting the appeal of the project. Furthermore, the lack of connection to other neighborhoods limited the utility of the new bikeways for residents.

Finally, bikeways implemented with an insufficient planning process may fail to bring benefits to a community. Various case studies in LA and other American cities show that there are unintended negative outcomes and local tensions when meaningful community engagement is not considered in bicycle infrastructure planning [4].
Equitable bikeway expansion calls for community participation and public consultation to assess who is benefiting and how bikeway expansion is reaching diverse communities. Hoffman's ethnographic research highlights the importance of contextualizing the neighborhood's history to understand community reactions to local bikeways and to engage the community from the beginning of the planning process [5]. In addition to disaggregated data, cities could invest in engaging community stakeholders across gender, age, race, economic, and ethnic backgrounds. This process includes increasing the voice of minoritized communities in transportation agencies and community engagement strategies [6].

In this way, pursuing participatory methods, community engagement, neighborhood ethnographic studies, historical references, and social network data can enrich future studies and complement quantitative metrics. These approaches will make visible the potential differential impacts of bikeway expansion in diverse communities and help local governments prioritize investment where it is needed the most. Only then can bikeway expansion provide more equitable long-term outcomes.

\section{Conclusion}

Bikeway development has expanded in recent years across the globe as a key strategy to foster sustainable development. However, there are increasing concerns that such investment may result in gentrification and potential displacement of low-income communities and communities of color.

The case study findings suggest there was little to no correlation between bikeway development and gentrification or displacement in LA between 2010 and 2015. We then enumerated the many limitations of quantitative data in this type of study and suggested how qualitative data may be a more effective tool to forge an agreement among planners and communities as to the definition and measurement of gentrification. We cannot conclusively dismiss the relationship between bikeway development and gentrification or displacement in Los Angeles without such consensus.

Furthermore, the results of our study may not be universal across geography or over time as transportation networks evolve. Future transportation studies will benefit from both better quantitative and qualitative data, as well as deeper engagement with and representation of minoritized communities.

\section{Acknowledgements}

The authors would like to thank the MIT Institute for Data Systems, and Society and the organizing team of the MIT Policy Hackathon 2020 for bringing us together and making this research possible. We would also like to thank Marisa Laderach, Hannah Keyes, and the Southern California Association of Governments (SCAG) team for providing the data and supporting the case study analysis, and Emmett McKinney for providing relevant theoretical and conceptual contributions for this piece.

\section{Citation}


Soria, L., Cohen, J., Molas y Molas, M. F., Rizk, M., \& Wisambodhi, P. Equitable bikeway expansion: investigating potential links to gentrification and displacement. MIT Science Policy Review 2, 55-62 (2021). https://doi.org/10. $38105 /$ spr. la2mv0fj4g.

\section{Open Access}

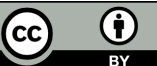

This MIT Science Policy Review article is licensed under a Creative Commons Attribution 4.0 International License, which permits use, sharing, adaptation, distribution and reproduction in any medium or format, as long as you give appropriate credit to the original author(s) and the source, provide a link to the Creative Commons license, and indicate if changes were made. The images or other third party material in this article are included in the article's Creative Commons license, unless indicated otherwise in a credit line to the material. If material is not included in the article's Creative Commons license and your intended use is not permitted by statutory regulation or exceeds the permitted use, you will need to obtain permission directly from the copyright holder. To view a copy of this license, visit http://creativecommons.org/licenses / by $/ 4.0 /$.

\section{Legislation Cited}

(1) CA. Const. art. XIII.

\section{References}

[1] United Nations High-level Advisory Group on Sustainable Transport. Mobilizing sustainable transport for development (2016). Online: https://sustainabledevelopment. un.org/content/documents/2375Mobilizing\% 20.Sustainable\%20Transport.pdf.

[2] Bauman, A. E. \& Rissel, C. Cycling and health: An opportunity for positive change? Medical Journal of Australia 190, 347-348 (2009). Online: https://doi.org/10.5694/j. 1326-5377.2009.tb02443.x.

[3] Mason, L., Fulton, L. \& McDonald, Z. A global high shift cycling scenario: The potential for dramatically increasing bicycle and E-bike use in cities around the world, with estimated energy, $\mathrm{CO} 2$, and cost impacts. Institute for Transportation Development Policy, Transport Matters (2015). Online: https://www.itdp.org/2015/11/12/a-globalhigh-shift-cycling-scenario/.

[4] Lugo, A. E. Bicycle/Race: Transportation, Culture, \& Resistance (Microcosm Publishing, 2018).

[5] Hoffman, M. L. Bike Lanes Are White Lanes: Bicycle Advocacy and Urban Planning (University of Nebraska Press, 2016).

[6] Coalition, S. F. B. Bike lanes, gentrification, and anti-Blackness (2020). Online: https://sfbike.org/bike-lanesgentrification-and-anti-blackness/.

[7] Delmelle, E. C., Nilsson, I. \& Bryant, A. Investigating transit-induced displacement using eviction data. Housing Policy Debate 1-16 (2020). Online: https://doi.org/10.1080/ 10511482.2020 .1815071$.

[8] Schlichtman, J. J., Patch, J. \& Hill, M. L. Gentrifier (University of Toronto Press, 2017).

[9] Easton, S., Lees, L., Hubbard, P. \& Tate, N. Measuring and mapping displacement: The problem of quantification in the battle against gentrification. Urban Studies 57, 286-306 (2019). Online: https://doi.org/10.1177/0042098019851953.

[10] Grier, G. W. \& Grier, E. S. Urban Displacement: A Reconnaissance (Grier Partnership, 1978).
[11] Davidson, M. Displacement, space and dwelling: Placing gentrification debate. Ethics, Place Environment 12, 219-234 (2009). Online: https://doi.org/10.1080/ 13668790902863465.

[12] Mendelson, A. Watch a decade of growth in LA's bike infrastructure (2015). Online: https: / /www.scpr.org/news/ 2015/04/10/50849/watch-a-decade-of-growth-inla-s-bike-infrastructu/.

[13] LADOT. Transportation service: More options to get around Online: https://ladot.lacity.org/projects/ transportation-services\#buses.

[14] LADOT. Vision Zero is Los Angeles's commitment to eliminate traffic deaths by 2025 Online: https: //ladotlivablestreets.org/programs/vision-zero.

[15] Southern California Alliance of Governments Bike routes-SCAG region. Online: https:// gisdata-scag.opendata.arcgis.com/datasets/ 995a9a5ef43944a7bdaec45ca9540190_0/data.

[16] City of Los Angeles. Los Angeles geohub, bikeways existing (2015). Online: https://geohub. lacity.org/datasets/ lahub: : bikeways-existing/about.

[17] Chapple, K. et al. Developing a new methodology for analyzing potential displacement. UC Berkeley Center for Community Innovation (2017). Online: https://communityinnovation.berkeley.edu/sites/ default/files/developing_a_new_methodology_ for_analyzing_potential_displacement.pdf?width= 1200 \&height $=800$ \& if rame $=$ true.

[18] U.S. Census Bureau. 2010-2015 American Community Survey subject tables. Online: https://www.census.gov/acs/ www/data/data-tables-and-tools/subject-tables/.

[19] Eviction Lab. Eviction map \& data. Online: https:// evictionlab.org/get-the-data/.

[20] County of Santa Clara. Understanding proposition 13 Online: https://www.sccassessor.org/index.php/ faq/understanding-proposition-13.

[21] Gil, J. Street network analysis "Edge Effects": Examining the sensitivity of centrality measures to boundary conditions. Journal of Transport Geography. 44 (2016). Online: https://doi. org/10.1177/0265813516650678.

[22] Sevtsuk, A. Urban Network Analysis. Tools for Modeling Pedestrian and Bicycle Trips in Cities (Harvard Graduate School of Design., Cambridge, MA, 2018). Online: https://www.dropbox.com/s/prog3r1j6x0m89y/UNA_ user_guide_2018.pdf?dl=0.

[23] U.S. Census Bureau, Geography Division. Tiger/line shapefiles: Census tracts Online: https://www.census.gov/cgi-bin/ geo/shapefiles/index . php ? year=2015\&layergroup= Censustrracts.

[24] U.S. Census Bureau. Understanding and using American community survey data, understanding error and determining statistical significance 44-50 (2018). Online: https: //www.census.gov/content/dam/Census/library/ publications/2018/acs/acs_general_handbook_ 2018_ch07.pdf.

[25] Preis, B., Janakiraman, A., Bob, A. \& Steil, J. Mapping gentrification and displacement pressure: An exploration of four distinct methodologies. Urban Studies 58, 405-424 (2021). Online: https://doi.org/10.1177/0042098020903011.

[26] Bousquet, C. Where is gentrification happening in your city? Using mapping to understand gentrification and prevent displacement. Data-Smart City Solutions, Ash Center, Harvard Kennedy School (2017). Online: https: //datasmart.ash. harvard.edu/news/article/whereis-gentrification-happening-in-your-city-1055.

[27] lacono, M., Krizek, K. \& El-Geneidy, A. Measuring non-motorized accessibility: Issues, alternatives, and execution. Journal of Transport Geography 18, 133-140 (2010). Online: https: //doi.org/10.1016/j.jtrangeo.2009.02.002. 
[28] Marshall, W. E. \& Ferenchak, N. N. Why cities with high bicycling rates are safer for all road users. Journal of Transport Health 13, 100539 (2019). Online: https://doi.org/10.1016/j. jth.2019.03.004.

[29] Schmitt, A. \& Brown, C. Right of Way: Race, Class, and the Silent Epidemic of Pedestrian Deaths in America (Island Press, 2020). Online: https://books.google.com.ar/books? id=7A7tDWAAQBAJ.

[30] Barajas, J. \& Braun, L. M. Are cycling and walking good for all? Tracking differences in associations among active travel, socioeconomics, gentrification, and self-reported health. Pre-print (2020). Online: https://osf.io/preprints/ socarxiv/fe785/.

[31] Butler, T. How to grow the bike community: 3 ideas from Tamika Butler (2019). Online: https://www.peopleforbikes. org/news/how-to-grow-the-bike-community-3ideas-from-tamika.

[32] Linton, J. Wilmington's new bike lane network, and what it does and doesn't do (2014). Online: https://la.streetsblog. org/2014/09/11/wilmingtons-new-bike-lanenetwork-and-what-it-does-and-doesnt-do/. 